\title{
Multimedia Authoring Systems For Constructing Education Packages For Special Needs Education
}

\author{
J. Fowler and S.Swales
}

\author{
School Of Computing And Information Systems, University Of Sunderland \\ Priestman Building, Green Terrace, Sunderland, Tyne \& Wear, United Kingdom, SR1 3SD.
}

\begin{abstract}
There are many problems involved with using "off-the-shelf" educational packages in Special Needs Education. For instance, commercial packages have, in the past, been found to accomplish only about half the function requires, or are found not to meet the needs of the pupils at all. An additional problem, is that these pupils often require special hardware which caters for their individual needs. There seems to be a complete lack of software which can be configured for the use of these special devices, which would enable the individual pupils to use the various programs.
\end{abstract}

This paper contains details of proposed research, which is currently underway, looking into specifying, designing and developing a system, which would allow teaching staff at such Spzcial Needs Schools to construct their own customised software for teaching purposes. With the use of such a system, software would be individually tailored to meet the needs of the pupils, and more accurately adjusted to the material being used in the curriculum of the time.

The proposed system would consist of a multi-media authoring system, which together with an easy-to-grasp user interface, would allow teachers to build their own stand-alone packages without the need to know a programming language.

\section{Introduction - Computers in the Classroom}

The use of computers as an aid to teaching in the classroom has become well established in recent years. They are widely used throughout the education system from kindergarten to higher education. Most subject areas employ computer applications to some extent and they have proved to be of particular benefit in special needs education $[1],[2],[3]$.

There have been many initiatives to establish the use of computers in teaching. In the early 1980's the British government aimed to provide every school (including Special needs schools) in the country with at least one computer.

Many schools have been able to grasp the opportunity to use computers in teaching. In other schools, however, their use has been limited. The reasons teacher resistance to computer use are varied [4],[5] but will include a lack of resources, time to develop the software, resistance to change [6],[7], and a lack of appropriate educational programs. 
Where the potential of computers has been recognised by teachers, (special school teachers in particular could see the benefits) the lack of educational software still has had to be addressed.

This could be done in a number of ways:

1. Software packages could be bought in. The drawback of this approach is that schools have a very limited budget and buying the wrong software could often be an expensive mistake.

2. Teaching staff could develop their own programs based on a their expert subject knowledge. This approach has a high probability of producing appropriate software with a sound educational value. Unfortunately in order to achieve this the teacher has to devote an enormous amount of time to developing such programs, in terms of both the teaching subject content and in their having to master the computer systems and software. They have to learn everything about the computer system from scratch, and for many the task has been too much.

3. A better approach was to employ computer experts to work in collaboration with the teachers to produce educational software[8]. The end product would usually be much better because the teacher avoided the need to learn how to program and was free to concentrate on the teaching material content. Again although this was highly successful there was still a high financial cost involved in this type of collaborative project.

A compromise solution to the problem of educational software production was to use packages to produce CAL courseware[9],[10]. Such systems claim to provide a user friendly interface which takes the pain out of programming[11]. Whereas it is the case that developing courseware through this type of system requires less programming than a conventional language there is nevertheless still a programming language to learn.

The aim of this project is to produce an authoring package which will enable teachers to easily produce computer based teaching materials without the need to directly write computer programs.

\section{The Development System}

It has been decided that we should use the Commodore Amiga 4000 multimedia workstation as a base for the development system[15]. The grounds for the use of this system are given below:

\section{Ease Of Use:}

The Amiga series of microcomputers are about the most user-friendly systems that we have encountered so far. It has been observed that a user, new to this particular system took less than half an hour to familiarise themselves with how 
the machine operated and had a word processing package up and running and in use in under an hour from first plugging the machine in and turning it on.

\section{Hardware:}

The Amiga series of computers are all based around the Motorola $680 \times 0$ family of microprocessors. The development system, the Amiga 4000 is available with either a 68030 or 68040 32-bit microprocessor. As well as this the Amiga systems have a number of custom support microprocessors which specifically handle things such as graphics, sound, memory and I/O functions. In short all the main processor actually contributes to this setup is the maths functions and provides the base instruction set. This combination of microprocessors adds up to an impressive machine, capable of running virtually any type of application at more or less peak efficiency.

\section{Graphics:}

The graphics capabilities of the Amiga are well known as being some of the best available on a low cost computer system. With a wide range of graphics modes and resolutions, with a 16.8 million colour palette available, and the provision of a graphics animation co-processor which can animate objects at high speeds.

\section{Sound:}

The sound capability of these machines features full voice synthesis, and sampling of real life sounds in four channel stereo. One of the most useful features of the sound system is the speech synthesis facility. This has been employed on another project called Art Master, which was an art package for use with special needs education. This employed the speech synthesizer to act as a computerised "instructor" which taught the children how to use the package with the minimum of teacher interaction. This proved to be very effective.

\section{Operating System:}

The Amiga is equipped with a highly efficient DOS known as AmigaDOS which is a fully multitasking system i.e. more than one program can be executed at once. AmigaDOS has the facility for recognising, reading and writing disks from other operating systems such as PC or Macintosh as well as its own formats.

\section{Compatibility:}

The Amiga is practically unique as far as considering compatibility between systems. This particular computer system has the ability to be given multiple "personalities." With the addition of low-cost expansion cards, it is possible to make the machine completely IBM PC compatible, right up to 486 standard, or make it completely Apple Macintosh compatible, BBC micro compatible or because of its superb multitasking abilities it is possible to have it running 
applications for all three personalities at once as well as its own native mode. It is even capable of running UNIX with the addition of an AMIX card.

Because of this unique feature, it is envisaged that the proposed multimedia system could well be used to produce programs which are IBM PC, Macintosh or BBC micro compatible as well as those which would run on Amiga systems. This would be particularly useful as it has been observed that there are plenty of schools in the U.K. which have a mixture of machines available to them. In short, a single Amiga system could be used to produce classroom software for all their systems.

\section{Availability:}

There are many schools which have adopted the Amiga as a classroom machine. This in many cases seems to be a growing trend. Also, the low-end Amigas are very popular in homes all over the country, this means that if a teacher wished to, the children who had these machines could take the classroom programs home to work on them. In the case of special needs children, this could be very important, as the child might not be in a position to be able to come into school. In which case a low-cost low-end system could be provided, equipped with programs put together by the teachers at the school.

All the Amiga range of computers from the low-end Amiga A500 right up to the high-end Amiga 4000/040 would be able to run the software created with this multimedia based authoring system. The authoring system itself should be useable on any of the "big box" Amigas equipped with a CD-ROM drive i.e. Amigas A1500, A2000, A3000 and A4000. As can be seen the above features make the Amiga the ideal machine for setting up the authoring system on.

\section{The Proposed System}

There is a need within special needs education for some way to customise software, so that it is truly usable in the classroom, as opposed to some package being bought "off-the-shelf," which may do some of the job or none of it at all.

The idea being that a system would be developed, which would enable staff within special needs education schools (or mainstream schools for that matter) to produce their own educational programs for use in the classroom.

One of the main problems teachers have in developing their own systems, is the time which is required to learn computer programming languages. The proposed system is designed to take away the need to learn any of these languages, and so shortens the time which is needed to learn enough about their computer system in order to use it, is reduced to an absolute minimum. It is envisaged that all the teaching staff would need to learn to use this program building tool, is how to use a mouse controller and how to make selections from a graphical user interface (GUI) driven icon and menu system. 
This lays a heavy emphasis on a user interface design which should be both easy to use and easy to understand[12][13][14]. It would be ideal if most of the operating manual could be reduced to a few pages telling the user how to get the package running, and then the package should be easy enough to use without needing the manual.

Over the years this has seemed to many people as being a very difficult thing to achieve. However, if the package is designed to operate in a very logical and sequential manner, then theoretically it should be quite difficult to make mistakes while using it. If the user had missed something out, which would prevent the finished classroom program from running, the development system should be able to tell the user this, and give the user an appropriate indication as to what it is that is missing, before the final product is put together and made into a stand-alone, self-running program.

There are several different authoring systems available on Amiga systems. This includes packages such as Scala MM300, AmigaVision, CanDo and the newly released Mediapoint system[16]. All of these systems allow users to construct "presentation" style applications. Some do allow the production of stand-alone programs, but all the ones which do this, require the user to use a script language or write some program code to do different things. This can be obstructive as far as the time necessary to learn them goes. The exception to this is the new MediaPoint system which uses a point and click graphical user interface..

The system that has been proposed, is somewhat different to these packages, in that the programs it would produce will be stand-alone, i.e. they will run by themselves. This will mean that there need only be one development machine equiped with the authoring system. All the programs produced should be runnable on all models of Amiga computer systems, so the classroom machines could be lower cost systems such as the Amiga A1200.

The system would use a set of module library CD-ROMs which would contain a large amount of program "segments" which can be added together via a specially designed program editor, to construct the final stand-alone program.

The authoring system therefore, would consist of the following parts:

\section{The Program Editor:}

This together with its easy-to-use user interface, would be the main driving program for the system. This would allow the teacher using the development system to actually plan out and create the classroom software that is required.

\section{The Program Compiler:}

This part of the system takes the program design taken created with the program editor and constructs the stand-alone program from the program modules libraries on CD-ROMs. 


\section{The CD-ROM module libraries:}

These CD-ROMs would hold the program modules, as mentioned above. The CD-ROMs would contain program segments which can be used to cover the whole curriculum.

\section{Conclusions}

There is clearly a need for the authoring system outlined above in Special Needs Education. There are many possible benefits. For instance, an authoring system which can be used for multi-machine format development has obvious benefits, i.e. most of a particular school's equipment could be utilised. Classroom software produced with such a system, rather than becoming obsolete when a curriculum change occurs, can simply be brought back into the development system and edited accordingly. The classroom software can also be tailored exactly to the requirements of the teachers concerned.

The major part of this work in developing the authoring system, will be the user-interface design. This process should be useful in establishing a methodology for constructing "intuitive" user interfaces for multimedia applications as a whole. The modular CD system is open ended, so new subjects and new program modules can be added to the development system with relative ease.

Research and development work on this system will be continuing with the emphasis on the construction of the user interface first. Once this has been completed, a generic development system will be produced which can be used to write classroom software within a limited subject area. This generic system will be used in field trials in a local Special Needs School, in order to evaluate the system. If the evaluation is successful then further subject areas will be added to the system.

\section{References}

1. Berg M., 'Computerised system for special needs', Computer Education, p.30, Feb. 1993.

2. Bailey J., 'Curriculum approaches in special education computing', Journal of Computer-based Instruction, p.1-5, Winter 1992.

3. Wood D. L., 'The Characteristics of intrinsically motivating early childhood and special education software', proc. IFIP TC 3 fifth world conference on Computers in Education, July 1990.

4. Hannafin R., Savenye W., 'Technology in the classroom: The Teacher's new Role and Resistance to it', Educational Technology, p26-31, June 1993. 
5. Drew D., 'Why Don't all professors use computers?', Academic-Computing, p12-14, 58-60, Oct 1989.

6. Kolehmainen P., 'The Changes in Computer Anxiety in a required computer course', proc. European conf. on Educational Research, The Netherlands, June 1992.

7. Crowe B., 'Computers in the Secondary Art Curriculum', Annual meeting of the Mid-South Educational Research Association, Lexington USA, Nov. 1988.

8. 'Marketing Education Computer Curriculum. Final Report.', Pittsburgh Univ., School of Education, 1988.

9. Pyzdrowski A., DeNardo A., 'Creating a computer simulator package for a hypothetical computer architecture', proc. Ann. conf. Eastern Educational Research Assn., March 1992.

10. McCluskey C., 'Interactive Video in the Classroom', proc. Nat. Staff Dev. Conf. Nat. council of States on Inservice education', Nov. 1985.

11. Motteram G., 'Using Standard Authoring packages to teach effective reading skills', p. 15-21, System, V18 n1, 1990.

12. Waterworth J., 'Multimedia technology and application', Ellis Horwood 1991

13. Tway L., 'Welcome To Multimedia', MIS Press 1992

14. Maybury. M. T., 'Intelligent Multimedia Interfaces', American Association for Artificial Intelligence 1993.

15. Fowler J., Swales S., 'Art Master - A Package For Special Needs Education (Paper)' Proc. AETT 29th International Conference, Edinburgh 1994

16. Amiga Shopper Magazine, Future Publishing Ltd., Issue 37, May 1994 